\title{
A Practical Review of Cytomegalovirus in Gastroenterology and Hepatology
}

\author{
Ali Y. Fakhreddine $\mathbb{D}^{1},{ }^{1}$ Catherine T. Frenette, ${ }^{1,2}$ and Gauree G. Konijeti $\mathbb{D}^{1}$ \\ ${ }^{1}$ Division of Gastroenterology and Hepatology, Scripps Clinic, La Jolla, CA, USA \\ ${ }^{2}$ Division of Organ Transplantation, Scripps Green Hospital and Scripps Clinic, La Jolla, CA, USA \\ Correspondence should be addressed to Gauree G. Konijeti; konijeti.gauree@scrippshealth.org
}

Received 3 December 2018; Accepted 5 February 2019; Published 7 March 2019

Academic Editor: Takayuki Yamamoto

Copyright (c) 2019 Ali Y. Fakhreddine et al. This is an open access article distributed under the Creative Commons Attribution License, which permits unrestricted use, distribution, and reproduction in any medium, provided the original work is properly cited.

\begin{abstract}
Human cytomegalovirus (CMV) is a ubiquitous Herpesviridae virus with a wide spectrum of pathology in humans. Host immunity is a major determinant of the clinical manifestation of CMV and can vary widely in the gastroenterology and hepatology practice setting. Immunocompetent patients generally develop a benign, self-limited mononucleosis-like syndrome whereas gastrointestinal tissue-invasive disease is more frequently seen in immunocompromised and inflammatory bowel disease patients. Additionally, liver allograft dysfunction is a significant consequence of CMV infection in liver transplant patients. While polymerase chain reaction and immunohistochemistry techniques allow for the reliable and accurate detection of CMV in the human host, the diagnostic value of different serologic, endoscopic, and histologic tests depends on a variety of factors. Similarly, latent CMV, CMV infection, and CMV disease carry different significance depending on the patient population, and the decision to initiate antiviral therapy can be complex and patient-specific. This review will focus on the pathophysiology, diagnosis, and management of CMV in patient populations relevant to the practice of gastroenterology and hepatology-liver transplant recipients, inflammatory bowel disease patients, and otherwise immunocompetent patients.
\end{abstract}

\section{Introduction}

Human cytomegalovirus (CMV) earns its name from the characteristic cytomegalic appearance of intranuclear inclusions in infected cells, an appearance first described in 1881 [1]. As a member of the Herpesviridae family, human herpes virus 5 (HHV 5), or CMV, is a double-stranded DNA virus capable of a wide spectrum of disease in humans. This review will focus on the diagnosis and management of CMV in the general population, liver transplant (LT) patients, and inflammatory bowel disease (IBD) patients.

\section{Transmission and Infection}

Transmission among adults can occur via exposure to bodily fluids including tears, saliva, semen, and blood or transplanted organ tissue. The main routes are via close contact with young children and intimate contact with adults such as kissing or sexual intercourse. Successful transmission is based on the frequency of these events and the chance of active viral shedding in the infected host [2].

Initial infection occurs in mucosal epithelial cells, and viral dissemination occurs via infected circulating CD14+ monocytes [3]. CMV has a remarkable doubling time of approximately one day, and clinical manifestations of infection increase proportionately to viral load [4]. In immunocompetent individuals, an initial immune response will result in controlling further replication and dissemination of virus, but a subsequent latent phase is universally present [5].

While human CMV is highly species-specific, it demonstrates broad tropism within the human body that includes parenchymal, connective tissue, and hematopoietic cells. In the liver, CMV most frequently infects hepatocytes and macrophages, whereas stromal and vascular endothelial cells are 
TABLE 1: Definitions and risk factors of the described CMV clinical entities in the general, IBD, and liver transplant patient populations.

\begin{tabular}{|c|c|c|}
\hline Disease manifestation & Definition & Risk factors \\
\hline \multicolumn{3}{|l|}{ General population } \\
\hline Latent CMV & $\begin{array}{l}\text { Asymptomatic, no clinically detectable } \\
\text { active replication }\end{array}$ & $\begin{array}{l}\text { Female sex, older age, high crowding index, and } \\
\text { low household income or education [2] }\end{array}$ \\
\hline $\begin{array}{l}\text { Mononucleosis-like } \\
\text { syndrome }\end{array}$ & $\begin{array}{l}\text { Predominant constitutional, mononucleosis-like } \\
\text { symptoms with intact immune system }\end{array}$ & $\begin{array}{l}\text { Blood transfusions, second or third decades of life, } \\
\text { exposure to bodily fluids of infected host [14] }\end{array}$ \\
\hline Tissue-invasive CMV & $\begin{array}{l}\text { Predominant symptoms localizable to } \\
\text { a specific tissue site }\end{array}$ & $\begin{array}{l}\text { Critical illness (especially with sepsis or } \\
\text { intubation at time of admission), active malignancy } \\
\text { (especially with low BMI, lymphopenia, or steroid use), } \\
\text { hematologic malignancy, blood transfusion [27] }\end{array}$ \\
\hline \multicolumn{3}{|c|}{ Inflammatory bowel disease ${ }^{*}$} \\
\hline Tissue-invasive CMV & $\begin{array}{l}\text { Predominant symptoms typically localizable } \\
\text { to the GI tract, mimicking IBD flare }\end{array}$ & $\begin{array}{l}\text { Endoscopic inflammation [107], } \\
\text { immunosuppressant-refractory ulcerative colitis }\end{array}$ \\
\hline \multicolumn{3}{|l|}{ Liver transplant ${ }^{* *}$} \\
\hline CMV syndrome & $\begin{array}{l}\text { Positive CMV serum PCR with } 2 \text { of the following: } \\
\text { (i) Fever } \geq 38^{\circ} \mathrm{C} \text { for at least } 2 \text { days } \\
\text { (ii) New fatigue or malaise } \\
\text { (iii) Leukopenia or neutropenia } \\
\text { (iv) } \geq 5 \% \text { atypical lymphocytes } \\
\text { (v) Platelets }<100,000 \text { cell } / \mu \mathrm{L} \text { or }>20 \% \text { decrease } \\
\text { (vi) }>2 \mathrm{xULN} \mathrm{ALT} \mathrm{or} \mathrm{AST}\end{array}$ & $\begin{array}{l}\text { R-/D+ status, acute allograft rejection, } \\
\text { immunosuppression with antilymphocyte antibodies, } \\
\text { mycophenolate dose }>2 \text { grams/day, viral coinfection, } \\
\text { toll-like receptor polymorphisms }[108]\end{array}$ \\
\hline Tissue-invasive CMV & $\begin{array}{l}\text { Predominant symptoms localizable } \\
\text { to a specific tissue site }\end{array}$ & \\
\hline
\end{tabular}

${ }^{*}$ Latent CMV and mononucleosis-like syndrome definition and risk factors are as with the general population. ${ }^{* *}$ Latent CMV definition and risk factors are as with the general population.

the primary target in the gastrointestinal (GI) tract [6-8]. Although smooth muscle and epithelial cells are also infected in the GI tract, inclusion bodies are rarely seen in epithelial cells around ulcer margins, supporting the common teaching of targeting the ulcer base during endoscopic biopsy of suspected CMV disease $[9,10]$.

Given the protean nature of CMV clinical disease following exposure, a set of universal terms is used to describe CMV pathology within the human host [11]. Latent $C M V$ refers to presence of CMV viral DNA within the human host without detectable, active replication. $C M V$ infection refers to evidence of active viral replication without symptoms, and CMV disease refers to CMV infection with overt symptoms.

\section{CMV in the General Population: Presentation, Diagnosis, and Management}

A minority of primary CMV infections in immunocompetent patients will result in symptoms. In such cases, a mononucleosis-like picture is seen with a variable degree of constitutional and organ-specific symptoms. In the general population, more severe tissue-invasive disease of the gastrointestinal tract or liver is almost always limited to patients with critical illness or comorbidities conferring relative immunosuppression.

3.1. Latent $C M V$. By far, the most common clinical status of $\mathrm{CMV}$ in humans is latent infection. Latent CMV is asymptomatic and diagnosed based on presence of CMV-specific
IgG antibodies. CMV seroprevalence in the United States is reported to be $42-93 \%$ [2]. Female gender, older age, non-Hispanic black and Mexican American ethnicity, crowding, low education level, and low household income were all independently associated with CMV seropositivity (Table 1) [2]. The role of latent CMV in the development of GI disease is limited. CMV has been demonstrated to preferentially replicate within dysplastic colonic epithelial cells, with effects of viral proteins on various tumor suppression genes such as Bcl-2 and p53. Causality of latent CMV in GI malignancy remains implied but has not yet been demonstrated [12]. No curative treatments for latent CMV exist currently.

3.2. Mononucleosis-Like Syndrome. The typical presentation of mononucleosis-like syndrome consists of prolonged fevers, myalgia, and malaise. Less than $5 \%$ of patients present with jaundice. Atypical leukocytes are almost always seen. The liver is a primary site of involvement with $70-90 \%$ of patients presenting with atypical liver chemistries and $10-38 \%$ of patients having hepatosplenomegaly [13]. The ALT, AST, total bilirubin, and alkaline phosphatase are usually elevated within 3x upper limit of normal (ULN) and rarely $5 x$ ULN. A mixed hepatocellular and cholestatic picture is generally seen [14].

Diagnosis of mononucleosis-like syndrome due to CMV should begin with exclusion of Epstein-Barr virus (EBV) mononucleosis. Proposed diagnostic algorithms suggest testing with CMV IgM only in patients with atypical leukocytes and negative EBV heterophile antibody and EBV IgM 


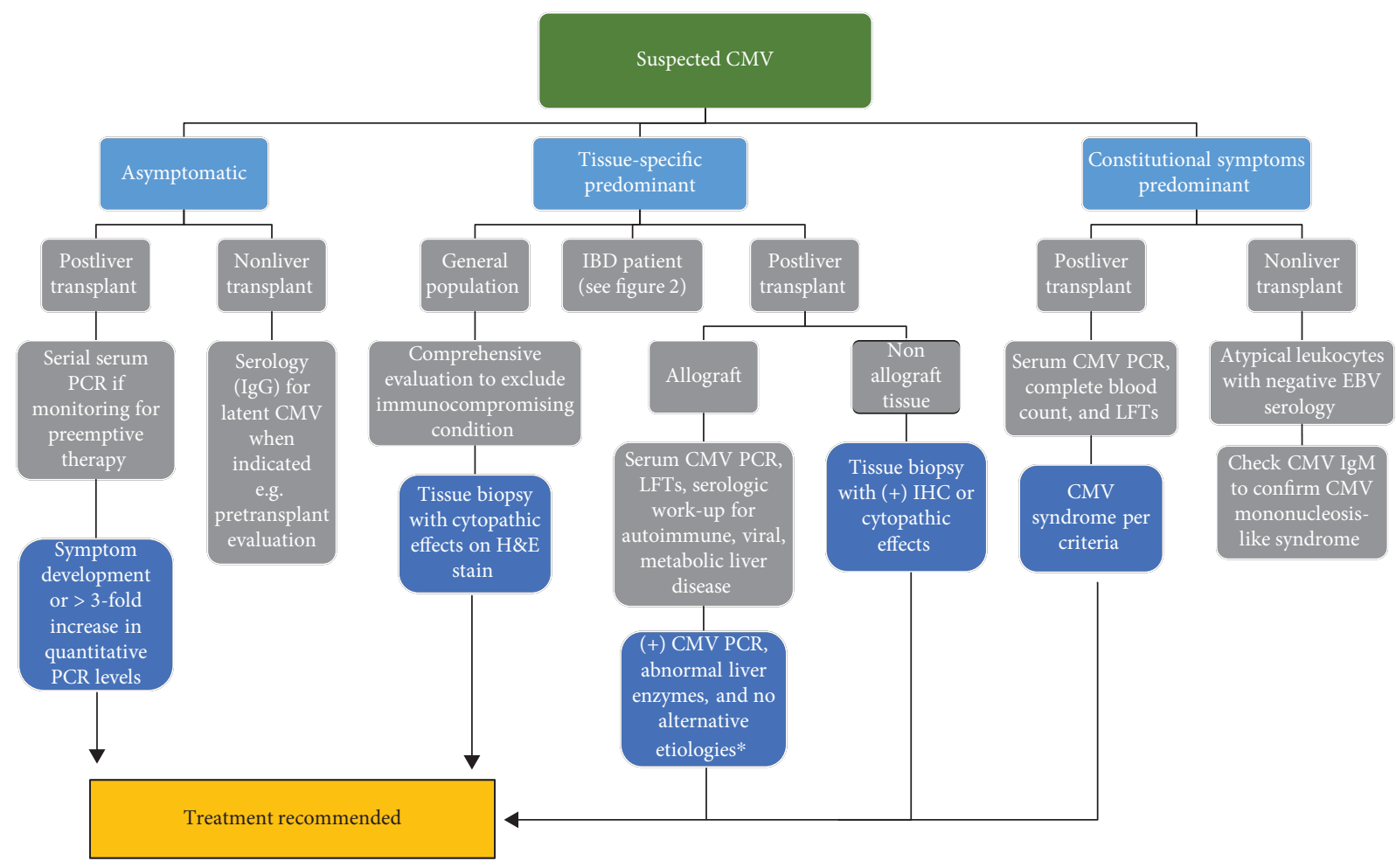

FIGURE 1: Flow diagram for diagnostic and management approach to patients with suspected CMV. ${ }^{*}$ Consider liver biopsy to rule out acute graft rejection. LFT: liver function tests.

(Figure 1). Polymerase chain reaction- (PCR-) based tests are not routinely recommended due to cost, potential for detection of latent CMV, and the adequate sensitivity and specificity of serology $[15,16]$.

Mononucleosis-like syndrome in immunocompetent patients is generally benign and self-limited. Although no high-quality studies exist regarding antiviral treatment of CMV mononucleosis-like syndrome, antiviral treatment for EBV mononucleosis, with or without steroids, has not demonstrated efficacy in clinically important outcomes $[17,18]$. Effective treatment with ganciclovir for severe CMV mononucleosis-like syndrome has been reported. However, in the absence of a controlled study, the true benefit of antiviral therapy over observation cannot be determined [19].

\subsection{Tissue-Invasive Disease}

3.3.1. Gastrointestinal. Tissue-invasive gastrointestinal (TI-GI) CMV is defined as CMV disease with symptoms localized to the GI tract. In the general population, TI-GI CMV disease almost always occurs in patients with relative immunosuppression due to critical illness or comorbidities such as type 2 diabetes mellitus, renal insufficiency, pregnancy, autoimmune diseases, heart failure, or malignancy [20-22].

In a systematic review of tissue-invasive CMV in patients with relative immunosuppression, the GI tract is most commonly involved and comprises $30 \%$ of tissue-invasive disease
[21]. In all patients undergoing endoscopy at one center, approximately $30 \%$ of TI-GI CMV cases occurred in patients without overtly compromised immunity or IBD, with an overall prevalence of approximately 3 in 1,000 endoscopies [10]. Among TI-GI CMV in this population, the colon is the most frequently reported site of involvement, comprising up to $94 \%$ of cases $[10,23,24]$.

Critical illness is a major risk factor for viral reactivation in otherwise immunocompetent patients, with approximately $3-4 \%$ of patients in the intensive care unit developing tissue-invasive CMV disease [25]. Active malignancy, especially hematologic malignancy when associated with low BMI and lymphopenia, is another particularly susceptible population. Blood transfusion is a well-identified risk factor among these two groups of patients (Table 1) [26, 27].

Clinical manifestations of TI-GI CMV vary and depend largely on site of involvement. Odynophagia occurs in over $60 \%$ of patients with esophageal involvement, whereas epigastric pain and hematochezia are more characteristic of gastric and colonic involvement, respectively [9]. Symptoms of fever, anorexia, weight loss, abdominal pain, nausea, vomiting, diarrhea, and hemorrhage can otherwise be present with involvement of any part of the GI tract. Endoscopic findings also range from mucosal inflammation and edema to pseudotumors and severe ulceration $[9,24,28]$.

3.3.2. Hepatic. Generally, tissue-invasive disease in the liver of relatively immunocompromised patients is similar to that in mononucleosis-like syndrome but with more frequent 
jaundice and higher levels of liver enzyme elevation [13]. Rare cases of fulminant hepatic failure secondary to CMV have been reported. Of note, the reported cases involved immunocompetent patients with histologic evidence of CMV based on staining but not classic cytopathic findings $[29,30]$. Histologic findings of granulomatous hepatitis have also been described in the setting of CMV infection [31,32].

3.3.3. Pancreatic. Acute pancreatitis secondary to CMV infection is well-established with confirmatory histologic evidence of infection mainly found in autopsy studies and pancreas allograft biopsies [33,34]. An autopsy study found that approximately $10 \%$ of patients with CMV infection have pancreas involvement, although selection bias of severe disease is expected [35]. Most diagnoses in case reports are based on acute pancreatitis in the setting of CMV viremia with demonstrated response to CMV treatment [36-38]. Cholangitis with CMV involvement of the biliary epithelium has also been reported [39]. Therefore, although rare, these clinical entities merit consideration, especially in immunocompromised patients.

3.4. Diagnosis. An important consideration in the diagnosis of tissue-invasive disease in the general population is the assumption of immunocompetence. Even in younger patients with no reported comorbidities, a certain subset presenting with CMV colitis is soon after diagnosed with IBD [40]. Patients with prominent tissue-invasive CMV should therefore be closely evaluated for immunocompromising conditions, concurrent IBD, or an alternative diagnosis (Figure 1) [41, 42].

A diagnosis of tissue-invasive CMV requires histopathologic demonstration of CMV involvement of the suspected organ. Cytopathic effects, such as inclusion bodies, are seen in only approximately $65 \%$ of cells that have positive CMV immunohistochemical (IHC) staining [43, 44]. IHC and mucosal PCR techniques appear complimentary as approximately $10-15 \%$ of diagnoses missed by one modality can be detected by the other [45].

In relatively immunocompetent patients, the clinical utility of tissue IHC staining or PCR over cytopathic effects in the diagnosis of CMV infection has been questioned. In one center, of approximately $600 \mathrm{GI}$ specimen IHC positive for CMV, none of the specimens without cytopathic effects resulted in a change in management or outcome [43]. This suggests that cytopathic changes such as inclusion bodies are the only clinically relevant histologic finding which might prompt treatment for CMV in the general population.

3.5. Management. Ganciclovir is an acyclic guanine nucleoside analog that is similar in structure to acyclovir but effective against CMV at concentrations 10 to 100 times lower due to an additional hydroxymethyl group [46]. Viral phosphorylation of ganciclovir occurs via UL97 during CMV replication, and subsequent phosphorylation is performed by cellular kinases to produce a competitive substrate for the CMV-DNA polymerase UL54 [47]. Mutations in the UL97 and UL54 genes are therefore the two mechanisms described for ganciclovir resistance.
Ganciclovir oral bioavailability is 6-9\%, and therefore, oral ganciclovir is not recommended for treatment of CMV. The L-valyl ester, a prodrug of ganciclovir, valganciclovir, has an oral bioavailability of $61 \%$, which improves by $25 \%$ if taken with food. Clinical trials in AIDS and solid organ transplant patients have demonstrated comparable efficacy and safety between intravenous ganciclovir and oral valganciclovir, with treatment efficacy of over $80 \%[48,49]$.

Randomized controlled trials of prophylaxis or treatment of CMV infection in critically ill patients have not shown benefits in any clinical outcomes such as mortality or length of stay [50, 51]. No guidelines exist for treatment of tissue-invasive disease in the general population, and discretion is generally left to the treating physician based on assessed risk and benefit. As with mononucleosis-like syndrome, successful treatment with the antivirals ganciclovir, valganciclovir, and foscarnet has been reported in the literature but in the absence of a controlled study [52-54]. Severe CMV disease, such as perforation or impending liver failure, certainly warrants antiviral therapy regardless of the perceived host immune status.

\section{CMV in IBD: Presentation, Diagnosis, and Management}

CMV is found in $10-38 \%$ of patients with active ulcerative colitis (UC) based on histology and mucosal PCR technique $[55,56]$. Detection of CMV in patients with active Crohn's disease $(\mathrm{CD})$ is less common, presumably due to the Th1-driven pathophysiology of CD resulting in high levels of IFN- $\gamma$ which inhibit CMV replication. TI-GI CMV is the most common manifestation of CMV disease in IBD, and given the similarity in clinical presentation with an acute IBD flare, determining the primary process clinically can be challenging.

Patients with active UC resistant to corticosteroids or multiple lines of immunosuppressive therapy are at an increased risk of clinically significant TI-GI CMV colitis. Approximately one-third of patients with steroidrefractory UC have TI-GI CMV, significantly more than steroid-responsive or inactive disease [57, 58]. Multiple cohort studies demonstrate an increased rate of histologic detection and virologic burden of CMV based on tissue IHC and DNA-PCR in patients with steroid-refractory UC compared to those with steroid-responsive disease [7, 57, 59]. Additionally, rates of surgery appear to be reduced by antiviral therapy in patients with histologic CMV and steroid-refractory disease, suggesting clinically significant TI-GI CMV [7].

On the other hand, corticosteroids as an independent risk factor for clinically significant TI-GI CMV have not been clearly established. In fact, Roblin et al. demonstrated that tissue CMV-PCR was predictive of steroid-refractory UC in a steroid-naïve patient population [60]. Other studies further suggested no association between prior steroid, immunomodulator, or biologic exposure and TI-GI CMV in patients with UC flare [27, 61]. Anti-TNF therapy has been repeatedly shown to have no discernable effect on 
CMV activation $[62,63]$. These findings suggest that rather than being activated by immunosuppressive therapy or steroids, CMV is a primary pathogen that induces nonresponse to immunosuppressive therapy in at least a subset of patients with refractory UC and TI-GI CMV.

4.1. Diagnosis. Diagnosis of TI-GI CMV in IBD currently relies on histology with IHC or mucosal PCR. In the setting of endoscopic mucosal disease, 11 and 16 biopsies were required from $\mathrm{UC}$ and $\mathrm{CD}$ patients, respectively, to achieve $80 \%$ probability of CMV detection in at least one biopsy [64, 65]. By comparison, only 3 biopsies were diagnostic in $80 \%$ of AIDS patients with CMV esophagitis and visible ulcers, suggesting that a higher number of biopsies are necessary to rule out $\mathrm{CMV}$ in the colon or in patients with IBD or both. Endoscopic features of CMV colitis cannot be reliably distinguished from active IBD without CMV and can include erythema, exudate, erosions, and deep ulcers $[66,67]$.

TI-GI CMV, especially in steroid-refractory UC, occurs almost exclusively in seropositive patients $[57,60]$. Therefore, CMV IgG testing can be considered as the first step of evaluation in patients with a low likelihood of latent CMV since a negative CMV IgG can preclude further testing. Other modalities of noninvasive evaluation are an unreliable surrogate for tissue-invasive CMV in patients with IBD. Between $33-50 \%$ of patients with biopsy-confirmed CMV colitis, including high tissue disease burden, can have negative serum PCR or antigenemia. Similarly, low-level antigenemia or serum PCR can be common especially in the setting of steroid or cyclosporine immunosuppression and generally self-resolves [68]. On the other hand, a high serum CMV viral load can be suggestive of steroid refractoriness in active UC $[65,69]$. Therefore, the absence of detectable serum CMV should not preclude further evaluation for CMV colitis; however, high serum levels may encourage treatment especially if invasive testing is being deferred $[65,68,69]$.

Small studies of stool-based PCR testing in patients with IBD have demonstrated a sensitivity and specificity of $67-83 \%$ and $93-96 \%$, respectively, compared to PCR of colonic mucosal biopsies [70, 71]. However, the clinical utility of this test is less certain.

Disease location is an important consideration when planning for endoscopy. In a study by McCurdy et al., TI-GI CMV disease was seen exclusively proximal to the splenic flexure in $50 \%$ of $\mathrm{CD}$ and only $9 \%$ of UC patients $[65,72]$. Therefore, whereas flexible sigmoidoscopy may suffice in most cases for UC, a colonoscopy may be necessary to sufficiently rule out CMV of the colon in other IBD patient populations.

4.2. Management. Treatment of CMV in patients with IBD should be reserved to patients where TI-GI CMV is felt to be a significant driver of GI inflammation. CMV as a pathogen in the setting of active IBD has been demonstrated in patients where antiviral therapy and reduction of immunosuppression have induced significant clinical improvement $[34,73]$. Untreated CMV infection in IBD is generally associated with increased risk of hospitalization, colectomy, and mortality compared to IBD patients without active CMV $[59,74-77]$. Studies that fail to demonstrate an effect of CMV infection on IBD outcomes may be accounted for by variances in the CMV burden, where reactivations associated with lower CMV burden are less likely to result in clinically significant CMV-driven disease [59, 68]. Since CMV infection in patients with IBD is associated with rare IHC staining in approximately $50 \%$ of histologic specimen, most cases of CMV in gastrointestinal tissue are likely reactivation due to local immune dysregulation that has no or minimal clinical consequences $[43,65,78]$.

High CMV tissue burden on the other hand has been shown to correlate with steroid-refractory IBD and response to antiviral therapy $[59,79]$. Roblin et al. demonstrated that a CMV PCR greater than 250 copies per mg of colon tissue was associated with resistance to three successive treatment regimens to UC, and $88 \%$ of these patients improved with intravenous ganciclovir [60]. A case-control study by Jones et al. demonstrated that antiviral therapy in IBD patients with high-grade CMV disease improved surgery-free survival especially when compared to low-grade CMV disease burden [79]. In case series and case-control studies of steroid-refractory UC, patients with positive IHC staining or tissue PCR, even in the absence of cytopathic changes, tend to respond to antiviral treatment with significantly lower rates of surgery or surgery-free survival $[7,57,67]$. Therefore, antiviral therapy in refractory UC with histologic evidence of CMV or UC patients with high burden of tissue CMV should be strongly considered (Figure 2).

Antiviral therapy in the setting of IBD as mentioned above is similar to the general population. Experience in the IBD community generally involves a 2-3-week course of antiviral therapy with intravenous ganciclovir $5 \mathrm{mg} / \mathrm{kg}$ twice daily for 5-10 days followed by valganciclovir $900 \mathrm{mg}$ daily for the remainder of the course $[57,60,80]$. An earlier transition to oral valganciclovir after 3-5 days of intravenous ganciclovir may be reasonable with early responders. Immunosuppression reduction, especially corticosteroids, azathioprine, and cyclosporine should be strongly considered in patients with high suspicion for TI-GI CMV based on increased risk of CMV reactivation with these medications in the solid organ transplant and IBD populations $[68,81]$. Depending on the clinical course, both antiviral and immunosuppression may be required to achieve clinical remission. In such a case, an anti-TNF agent would be preferred for the reasons mentioned previously.

Finally, intensive granulocyte and monocyte adsorptive apheresis (GMAA) twice a week has been shown equally effective in inducing clinical remission of active UC in patients with and without colonic TI-GI CMV based on IHC and PCR [82]. In fact, histologic resolution of CMV occurred in $73.3 \%$ of affected patients with intensive GMAA, compared with $87.5-100 \%$ histologic clearance with antiviral therapy $[57,60,82]$. GMAA however has several limitations. Efficacy has been best demonstrated in moderate-severe ulcerative colitis, patients without severe ulceration, and steroid-naïve patients. Even then, a randomized, doubleblinded, sham-controlled study in the United States, Europe, 


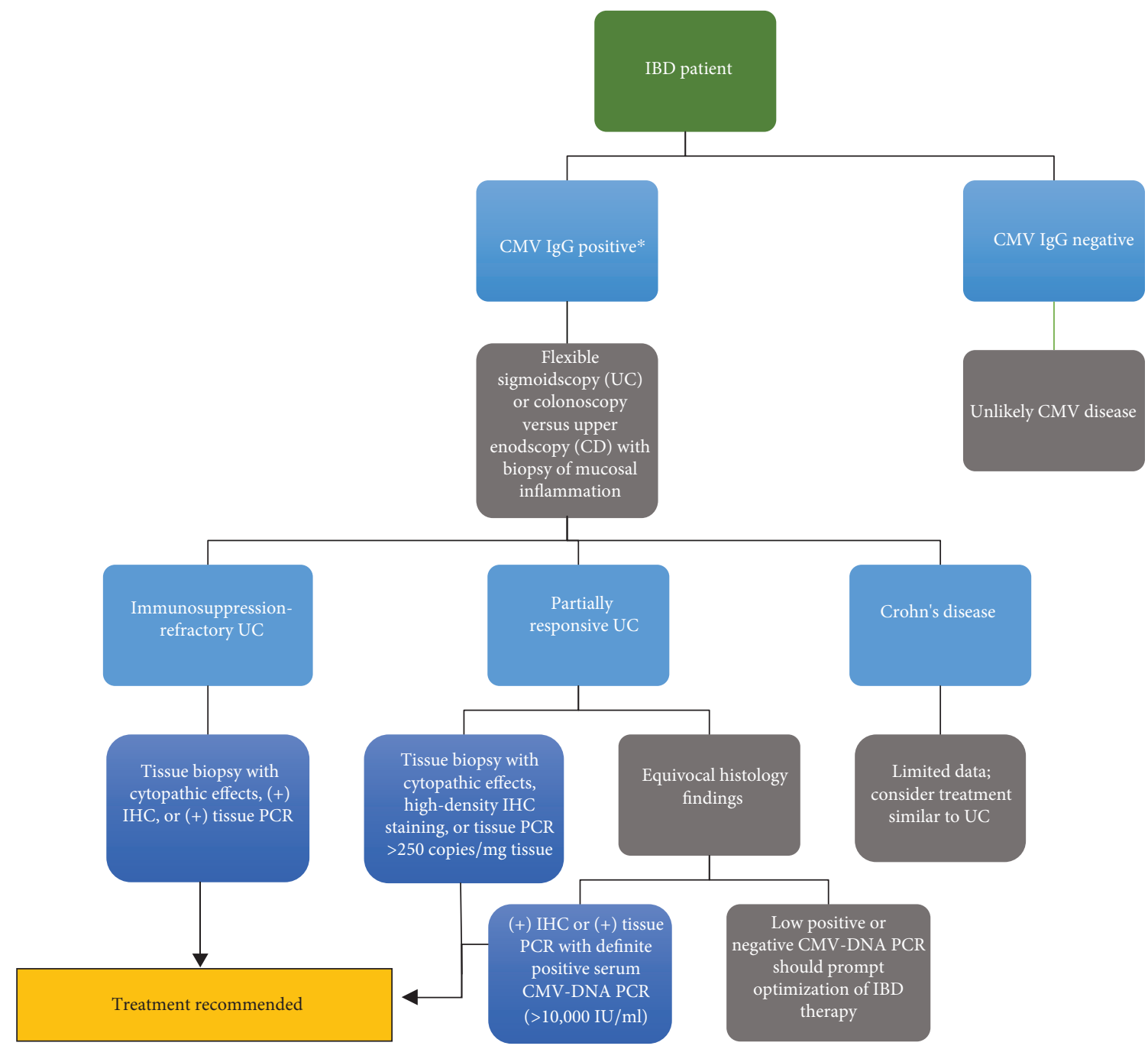

Figure 2: Flow diagram for diagnostic approach in patients with suspected CMV (continued). ${ }^{*}$ Not required. Should not delay endoscopic evaluation per routine care for active colitis.

and Japan failed to demonstrate benefit in moderate-severe ulcerative colitis [83]. Therefore, experience, availability, and insurance coverage in the United States are limited.

\section{CMV in Liver Transplant: Presentation, Diagnosis, and Management}

CMV infection is one of the most common opportunistic infections in patients following solid organ transplant (SOT) and occurs in up to $55 \%$ of post-LT patients [84]. Risk of infection is driven by a variety of factors including host comorbidities, posttransplant immunosuppressive protocol, allograft rejection, and most importantly patient and donor pretransplant CMV seropositivity [85]. A seronegative recipient and seropositive donor (R-/D+) match confers the highest risk for CMV infection with rates of $78-88 \%$ without prophylaxis, whereas D-/R- status confers the lowest risk and occurs in $0-13 \%$ of patients (Table 1) [84, 86].
CMV syndrome constitutes approximately $60 \%$ of CMV disease in LT patients and is characterized by a combination of constitutional, nonlocalizable symptoms, hematologic dyscrasias, and liver enzyme elevation [87]. Tissue-invasive disease most frequently involves the liver allograft due to aberrant local immune response, with detectable CMV in the allograft of $11-17 \%$ of post-LT patients. The gastrointestinal tract is the next most common site with clinical presentations similar to TI-GI CMV in other patient populations $[86,88]$.

The effects of CMV on allograft function extend beyond direct infection, however, as risks of acute and chronic allograft rejection are increased in patients with CMV infection [85]. Risks of bacteremia, invasive fungal disease, EBV-associated posttransplant lymphoproliferative disease, and cardiovascular disease are also increased in these patients $[85,89]$. Therefore, despite the efficacy of treatment of CMV disease or infection with antiretrovirals, prevention is a major strategy in post-LT patients. 
5.1. Diagnosis. Serology plays an important role pretransplant in detection of latent infection given implications on posttransplant risks of CMV infection and disease. While acute CMV infection can also be detected using IgM antibody or IgG antibody paired samples, the sensitivity of these tests in SOT patients is almost $50 \%$ at the time of symptom onset. By comparison, antigenemia and PCR have sensitivities of $79-80 \%$ and $84-100 \%$ in this setting, respectively [90-93]. These observations are explained by narrow detection windows and reliance of serology on an intact immune system $[47,93,94]$.

While diagnostic performance of antigenemia is generally comparable to PCR in the serum, its main limitations are reliance on an adequate neutrophil count, operator dependence, and the need to process samples within 6-8 hours. For all the reasons above, nucleic acid detection with serum PCR is the preferred test for real-time detection of CMV infection in LT patients [47].

A precise diagnosis of probable CMV syndrome can be made using criteria established by a panel of experts from the CMV Drug Development Forum which is based on demonstration of CMV viremia in addition to other clinical parameters that include liver enzyme elevation, thrombocytopenia, leukopenia, and presence of fatigue, malaise, or fever [11].

Diagnosing tissue-invasive disease of the allograft does not require histology and can be made based on CMV viremia, liver enzyme elevations, and exclusion of alternative causes of hepatitis. However, since CMV infection is a risk factor for allograft rejection and vice versa, a liver biopsy is generally performed to distinguish between these two processes [47].

Definite TI-GI is based on endoscopic and histologic evidence of CMV disease. Unlike the AIDS and IBD populations, no studies have examined the location of colonic TI-GI CMV in SOT patients. Since isolated ileal involvement with TI-GI CMV has been reported in posttransplant patients, initial investigation of suspected lower GI tract CMV disease with colonoscopy and ileal intubation would be prudent in this population until more data becomes available $[95,96]$.

5.2. Management. Universal prophylaxis for a minimum of 90 days is currently recommended based on the relatively higher degree of immunosuppression during this time period. Clinical trial data has shown up to $80 \%$ reduction of CMV infection with prophylaxis during the first 90 days after transplant [97]. In lower-risk patients, multiple randomized clinical trials in renal transplant patients have demonstrated comparable efficacy between universal prophylaxis and a strategy of preemptive therapy with weekly monitoring of serum CMV. A meta-analysis of retrospective studies in post-LT patients has largely supported this conclusion but suggested decreased graft loss with universal prophylaxis [98]. Results from a randomized clinical trial in LT patients are expected soon (NCT01552369).

Treatment for CMV should be initiated for CMV disease or increasing viremia in asymptomatic CMV infection (Figure 1). Generally, a greater than threefold increase in serum CMV PCR is considered significant [48, 99]. A large, multicenter, noninferiority trial of SOT patients did not demonstrate inferiority of oral valganciclovir to intravenous ganciclovir in viremia eradication or treatment success and showed comparable safety [49]. First-line treatment of CMV infection is therefore IV ganciclovir $5 \mathrm{mg} / \mathrm{kg}$ twice daily or valganciclovir $900 \mathrm{mg}$ twice daily adjusted for renal impairment, and efficacy of treatment is up to $85 \%$ in immunocompromised HIV/AIDS and postorgan transplant patients $[46,49]$.

Even after successful treatment of CMV disease, relapse rates can be as high as $27 \%$. Persistent viremia based on CMV PCR at completion of a 14-day course was associated with relapse; therefore, treatment until undetectable levels is recommended and can be continued until multiple negative levels are obtained, generally at least 2 weeks apart $[47,100]$. High CMV burden as evidenced by either viremia or severe tissue-invasive disease increases risk of relapse; however, endoscopic resolution of TI-GI disease was not predictive of relapse risk [101]. Secondary prophylaxis does not appear to confer a protective effect on relapse risk beyond delaying time to relapse while on treatment [102].

Another important consideration in the treatment of $\mathrm{CMV}$ is the level of immunosuppression, as generally decreasing immunosuppression will help with treatment. Use of mTOR appears to be associated with decreased incidence of CMV infection [103].

The incidence of ganciclovir-resistant CMV in LT patients is not well-defined but is relatively rare in SOT patients, ranging from $2 \%$ overall to $7 \%$ in high-risk R-/D+ patients $[104,105]$. Testing for resistance is available and can help guide treatment in nonresponders to first-line agents [106]. UL97 mutations will render ganciclovir and valganciclovir ineffective and can be circumvented with foscarnet and cidofovir. UL54 mutations are significantly more challenging and are generally approached with combination therapy involving first-line, second-line, and experimental treatments [106].

\section{Summary}

CMV infection and disease are frequently encountered entities in the practice of gastroenterology and hepatology. Direct detection via PCR and IHC has drastically improved our ability to detect CMV in host tissue; however, determining true CMV disease remains a clinical diagnosis and challenging in certain populations. Treatment decisions should therefore be based on a combination of factors assessing host immune status and viral burden. Valganciclovir is an effective treatment option for CMV infection in all patient populations and has significant impact on graft and patient survival in post-LT patients through prophylaxis and treatment.

\section{Conflicts of Interest}

Ali Youssef Fakhreddine, Guaree Gupta Konijeti, and Catherine Therese Frenette report no relevant conflicts of interest. 


\section{Authors' Contributions}

Ali Youssef Fakhreddine and Gauree Gupta Konijeti drafted and critically revised the manuscript. Catherine Therese Frenette critically revised the manuscript.

\section{References}

[1] H. Ribbert, "Ueber protozoenartige zellen in der niere eines syphilitischen neugeborenen und in der parotis von kindern," Zentralblatt für Allgemeine Pathologie und Pathologische Anatomie, vol. 15, pp. 945-948, 1904.

[2] S. L. Bate, S. C. Dollard, and M. J. Cannon, "Cytomegalovirus seroprevalence in the United States: the National Health and Nutrition Examination Surveys, 1988-2004," Clinical Infectious Diseases, vol. 50, no. 11, pp. 1439-1447, 2010.

[3] D. Collins-McMillen, J. Buehler, M. Peppenelli, and F. Goodrum, "Molecular determinants and the regulation of human cytomegalovirus latency and reactivation," Viruses, vol. 10, no. 8, p. 444, 2018.

[4] P. Griffiths, I. Baraniak, and M. Reeves, "The pathogenesis of human cytomegalovirus," The Journal of Pathology, vol. 235, no. 2, pp. 288-297, 2015.

[5] M. R. Wills, E. Poole, B. Lau, B. Krishna, and J. H. Sinclair, "The immunology of human cytomegalovirus latency: could latent infection be cleared by novel immunotherapeutic strategies?," Cellular \& Molecular Immunology, vol. 12, no. 2, pp. 128-138, 2015.

[6] C. Sinzger, A. L. Bissinger, R. Viebahn et al., "Hepatocytes are permissive for human cytomegalovirus infection in human liver cell culture and in vivo," The Journal of Infectious Diseases, vol. 180, no. 4, pp. 976-986, 1999.

[7] N. Kambham, R. Vij, C. A. Cartwright, and T. Longacre, "Cytomegalovirus infection in steroid-refractory ulcerative colitis: a case-control study," The American Journal of Surgical Pathology, vol. 28, no. 3, pp. 365-373, 2004.

[8] W. H. Roberts, J. M. Sneddon, J. Waldman, and R. E. Stephens, "Cytomegalovirus infection of gastrointestinal endothelium demonstrated by simultaneous nucleic acid hybridization and immunohistochemistry," Archives of Pathology \& Laboratory Medicine, vol. 113, no. 5, pp. 461464, 1989.

[9] D. M. You and M. D. Johnson, "Cytomegalovirus infection and the gastrointestinal tract," Current Gastroenterology Reports, vol. 14, no. 4, pp. 334-342, 2012.

[10] S. Patra, S. C. Samal, A. Chacko, I. Vadakenadayil, and M. MMM, "Cytomegalovirus infection of the human gastrointestinal tract," Journal of Gastroenterology and Hepatology, vol. 14, no. 10, pp. 973-976, 1999.

[11] P. Ljungman, M. Boeckh, H. H. Hirsch et al., "Definitions of cytomegalovirus infection and disease in transplant patients for use in clinical trials," Clinical Infectious Diseases, vol. 64, no. 1, pp. 87-91, 2017.

[12] L. Harkins, A. L. Volk, M. Samanta et al., "Specific localisation of human cytomegalovirus nucleic acids and proteins in human colorectal cancer," The Lancet, vol. 360, no. 9345, pp. 1557-1563, 2002.

[13] H. Leonardsson, J. P. Hreinsson, A. Löve, and E. S. Björnsson, "Hepatitis due to Epstein-Barr virus and cytomegalovirus: clinical features and outcomes," Scandinavian Journal of Gastroenterology, vol. 52, no. 8, pp. 893-897, 2017.
[14] J. I. Cohen and G. R. Corey, "Cytomegalovirus infection in the normal host," Medicine, vol. 64, no. 2, pp. 100-114, 1985.

[15] Y. F. Tsaparas, M. L. Brigden, R. Mathias, E. Thomas, J. Raboud, and P. W. Doyle, "Proportion positive for Epstein-Barr virus, cytomegalovirus, human herpesvirus 6, toxoplasma, and human immunodeficiency virus types 1 and 2 in heterophile-negative patients with an absolute lymphocytosis or an instrument-generated atypical lymphocyte flag," Archives of Pathology \& Laboratory Medicine, vol. 124, no. 9, pp. 1324-1330, 2000.

[16] G. H. Taylor, "Cytomegalovirus," American Family Physician, vol. 67, no. 3, pp. 519-524, 2003.

[17] M. De Paor, K. O’Brien, T. Fahey, and S. M. Smith, "Antiviral agents for infectious mononucleosis (glandular fever)," Cochrane Database of Systematic Reviews, 2016.

[18] E. Tynell, E. Aurelius, A. Brandell et al., "Acyclovir and prednisolone treatment of acute infectious mononucleosis: a multicenter, double-blind, placebo-controlled study," The Journal of Infectious Diseases, vol. 174, no. 2, pp. 324-331, 1996.

[19] R. B. Laing, R. S. Dykhuizen, C. C. Smith, and P. J. Molyneaux, "Parenteral ganciclovir treatment of acute CMV infection in the immunocompetent host," Infection, vol. 25, no. 1, pp. 44-46, 1997.

[20] T. H. Seo, J. H. Kim, S. Y. Ko et al., "Cytomegalovirus colitis in immunocompetent patients: a clinical and endoscopic study," Hepato-Gastroenterology, vol. 59, no. 119, pp. 2137$2141,2012$.

[21] P. I. Rafailidis, E. G. Mourtzoukou, I. C. Varbobitis, and M. E. Falagas, "Severe cytomegalovirus infection in apparently immunocompetent patients: a systematic review," Virology Journal, vol. 5, no. 1, p. 47, 2008.

[22] Y. Tachikawa, H. Nozawa, J. Tanaka et al., "Colonic perforation in a patient with systemic lupus erythematosus accompanied by cytomegalovirus infection: a case report," International Journal of Surgery Case Reports, vol. 23, pp. 70-73, 2016.

[23] C.-Y. Lee, Y.-H. Chen, and P.-L. Lu, "Reactivated cytomegalovirus proctitis in an immunocompetent patient presenting as nosocomial diarrhea: a case report and literature review," BMC Infectious Diseases, vol. 17, no. 1, p. 113, 2017.

[24] S. Jacob and N. R. Zayyani, "Cytomegalovirus colitis masquerading as rectal malignancy in an immunocompetent patient," Indian Journal of Pathology \& Microbiology, vol. 58, no. 1, pp. 80-82, 2015.

[25] R. Osawa and N. Singh, "Cytomegalovirus infection in critically ill patients: a systematic review," Critical Care, vol. 13, no. 3, p. R68, 2009.

[26] A. Al-Omari, F. Aljamaan, W. Alhazzani, S. Salih, and Y. Arabi, "Cytomegalovirus infection in immunocompetent critically ill adults: literature review," Annals of Intensive Care, vol. 6, no. 1, p. 110, 2016.

[27] J.-H. Ko, K. R. Peck, W. J. Lee et al., "Risk factors for cytomegalovirus gastrointestinal diseases in adult patients with cancer," European Journal of Clinical Microbiology \& Infectious Diseases, vol. 33, no. 10, pp. 1847-1853, 2014.

[28] L. Reggiani Bonetti, L. Losi, C. Di Gregorio et al., "Cytomegalovirus infection of the upper gastrointestinal tract: a clinical and pathological study of 30 cases," Scandinavian Journal of Gastroenterology, vol. 46, no. 10, pp. 1228-1235, 2011. 
[29] N. H. Shusterman, C. Frauenhoffer, and M. D. Kinsey, "Fatal massive hepatic necrosis in cytomegalovirus mononucleosis," Annals of Internal Medicine, vol. 88, no. 6, pp. 810-812, 1978.

[30] Y. D. Yu, G. C. Park, P. J. Park et al., "Cytomegalovirus infection-associated fulminant hepatitis in an immunocompetent adult requiring emergency living-donor liver transplantation: report of a case," Surgery Today, vol. 43, no. 4, pp. 424-428, 2013.

[31] M. Tjwa, G. De Hertogh, B. Neuville, T. Roskams, F. Nevens, and W. Van Steenbergen, "Hepatic fibrin-ring granulomas in granulomatous hepatitis: report of four cases and review of the literature," Acta Clinica Belgica, vol. 56, no. 6, pp. 341348, 2001.

[32] J. Clarke, R. M. Craig, R. Saffro, P. Murphy, and H. Yokoo, "Cytomegalovirus granulomatous hepatitis," The American Journal of Medicine, vol. 66, no. 2, pp. 264-269, 1979.

[33] S. Osiro, R. Muhammad, J. Ruiz, A. Sladen, N. Mathenge, and K. J. Tiwari, "Acute necrotizing pancreatitis in the setting of CMV viremia and AIDS: a case report and review of literature from 1980 to 2012," Journal of the Pancreas, vol. 13, no. 6, 2012.

[34] D. K. Klassen, C. B. Drachenberg, J. C. Papadimitriou et al., "CMV allograft pancreatitis: diagnosis, treatment, and histological features," Transplantation, vol. 69, no. 9, pp. 19681971, 2000.

[35] T. Iwasaki, A. Tashiro, R. Satodate, T. Sata, and T. Kurata, "Acute pancreatitis with cytomegalovirus infection," Acta Pathologica Japonica, vol. 37, no. 10, pp. 1661-1668, 1987.

[36] A. Chan, F. Bazerbachi, B. Hanson, M. Chadi Alraies, and A. Duran-Nelson, "Cytomegalovirus hepatitis and pancreatitis in the immunocompetent," Ochsner Journal, vol. 14, no. 2, pp. 295-299, 2014.

[37] L. Salazar-Huayna, E. Vélez-Segovia, J. Ruelas-Figueroa, F. Mendo-Urbina, and M. Montiel-Gonzales, "Cytomegalovirus pancreatitis in immunocompromised patients: a case report," Revista Colombiana de Gastroenterologia, vol. 29, no. 1, pp. 69-73, 2014.

[38] J. J. Schwartz, B. Woods, and F. Shihab, "A case of native cytomegalovirus pancreatitis following deceased-donor renal transplantation," The Open Transplantation Journal, vol. 3, no. 1, pp. 1-3, 2009.

[39] T. Oku, M. Maeda, E. Waga et al., "Cytomegalovirus cholangitis and pancreatitis in an immunocompetent patient," Journal of Gastroenterology, vol. 40, no. 10, pp. 987-992, 2005.

[40] P. Galiatsatos, I. Shrier, E. Lamoureux, and A. Szilagyi, "Meta-analysis of outcome of cytomegalovirus colitis in immunocompetent hosts," Digestive Diseases and Sciences, vol. 50, no. 4, pp. 609-616, 2005.

[41] E. Krajicek, R. Shivashankar, and S. Hansel, "Cytomegalovirus and the seemingly immunocompetent host: a case of a perforating gastric ulcer," ACG Case Reports Journal, vol. 4, no. 1, article e27, 2017.

[42] A. Maiorana, P. Baccarini, M. Foroni, N. Bellini, and F. Giusti, "Human cytomegalovirus infection of the gastrointestinal tract in apparently immunocompetent patients," Human Pathology, vol. 34, no. 12, pp. 1331-1336, 2003.

[43] I. H. Solomon, J. L. Hornick, and A. C. Laga, "Immunohistochemistry is rarely justified for the diagnosis of viral infections," American Journal of Clinical Pathology, vol. 147, no. 1, pp. 96-104, 2017.
[44] F. Colina, N. T. Juci, E. Moreno et al., "Histological diagnosis of cytomegalovirus hepatitis in liver allografts," Journal of Clinical Pathology, vol. 48, no. 4, pp. 351-357, 1995.

[45] A. M. Mills, F. P. Guo, A. P. Copland, R. K. Pai, and B. A. Pinsky, "A comparison of $\mathrm{cmv}$ detection in gastrointestinal mucosal biopsies using immunohistochemistry and pcr performed on formalin-fixed, paraffin-embedded tissue," The American Journal of Surgical Pathology, vol. 37, no. 7, pp. 995-1000, 2013.

[46] L. L. Brunton, B. A. Chabner, and B. C. Knollmann, Chemotherapy of Microbial Diseases. In: Goodman \& Gilman's The Pharmacological Basis of Therapeutics, McGraw-Hill, 12th edition, 2011.

[47] M. V. Dioverti and R. R. Razonable, "Cytomegalovirus," Microbiology Spectrum, vol. 4, no. 4, 2016.

[48] D. F. Martin, J. Sierra-Madero, S. Walmsley et al., "A controlled trial of valganciclovir as induction therapy for cytomegalovirus retinitis," The New England Journal of Medicine, vol. 346, no. 15, pp. 1119-1126, 2002.

[49] A. Åsberg, A. Humar, H. Rollag et al., "Oral valganciclovir is noninferior to intravenous ganciclovir for the treatment of cytomegalovirus disease in solid organ transplant recipients," American Journal of Transplantation, vol. 7, no. 9, pp. 21062113, 2007.

[50] N. J. Cowley, A. Owen, S. C. Shiels et al., "Safety and efficacy of antiviral therapy for prevention of cytomegalovirus reactivation in immunocompetent critically ill patients: a randomized clinical trial," JAMA Internal Medicine, vol. 177, no. 6, pp. 774-783, 2017.

[51] A. P. Limaye, R. D. Stapleton, L. Peng et al., "Effect of ganciclovir on IL-6 levels among cytomegalovirus-seropositive adults with critical illness: a randomized clinical trial," Journal of the American Medical Association, vol. 318, no. 8, pp. 731-740, 2017.

[52] M. Eddleston, S. Peacock, M. Juniper, and D. A. Warrell, "Severe cytomegalovirus infection in immunocompetent patients," Clinical Infectious Diseases, vol. 24, no. 1, pp. 5256, 1997.

[53] M. Fernández-Ruiz, C. Muñoz-Codoceo, F. López-Medrano et al., "Cytomegalovirus myopericarditis and hepatitis in an immunocompetent adult: successful treatment with oral valganciclovir," Internal Medicine, vol. 47, no. 22, pp. 19631966, 2008.

[54] C. Serna-Higuera, M. González-García, J. M. Milicua, and V. Muñoz, "Acute cholestatic hepatitis by cytomegalovirus in an immunocompetent patient resolved with ganciclovir," Journal of Clinical Gastroenterology, vol. 29, no. 3, pp. 276-277, 1999.

[55] E. Garrido, E. Carrera, R. Manzano, and A. Lopez-Sanroman, "Clinical significance of cytomegalovirus infection in patients with inflammatory bowel disease," World Journal of Gastroenterology, vol. 19, no. 1, pp. 17-25, 2013.

[56] J. J. Kim, N. Simpson, N. Klipfel, R. DeBose, N. Barr, and L. Laine, "Cytomegalovirus infection in patients with active inflammatory bowel disease," Digestive Diseases and Sciences, vol. 55, no. 4, pp. 1059-1065, 2010.

[57] E. Domènech, R. Vega, I. Ojanguren et al., "Cytomegalovirus infection in ulcerative colitis: a prospective, comparative study on prevalence and diagnostic strategy," Inflammatory Bowel Diseases, vol. 14, no. 10, pp. 1373-1379, 2008. 
[58] V. Criscuoli, A. Casà, A. Orlando et al., "Severe acute colitis associated with CMV: a prevalence study," Digestive and Liver Disease, vol. 36, no. 12, pp. 818-820, 2004.

[59] A. Kuwabara, H. Okamoto, T. Suda, Y. Ajioka, and K. Hatakeyama, "Clinicopathologic characteristics of clinically relevant cytomegalovirus infection in inflammatory bowel disease," Journal of Gastroenterology, vol. 42, no. 10, pp. 823-829, 2007.

[60] X. Roblin, S. Pillet, A. Oussalah et al., "Cytomegalovirus load in inflamed intestinal tissue is predictive of resistance to immunosuppressive therapy in ulcerative colitis," The American Journal of Gastroenterology, vol. 106, no. 11, pp. 2001-2008, 2011.

[61] T. Kojima, T. Watanabe, K. Hata, M. Shinozaki, T. Yokoyama, and H. Nagawa, "Cytomegalovirus infection in ulcerative colitis," Scandinavian Journal of Gastroenterology, vol. 41, no. 6, pp. 706-711, 2006.

[62] V. D’Ovidio, P. Vernia, G. Gentile et al., "Cytomegalovirus infection in inflammatory bowel disease patients undergoing anti-TNF $\alpha$ therapy," Journal of Clinical Virology, vol. 43, no. 2, pp. 180-183, 2008.

[63] S. Pillet, C. Jarlot, M. Courault et al., "Infliximab does not worsen outcomes during flare-ups associated with cytomegalovirus infection in patients with ulcerative colitis," Inflammatory Bowel Diseases, vol. 21, no. 7, pp. 1580-1586, 2015.

[64] C. M. Wilcox, R. F. Straub, and D. A. Schwartz, "Prospective endoscopic characterization of cytomegalovirus esophagitis in AIDS," Gastrointestinal Endoscopy, vol. 40, no. 4, pp. 481-484, 1994.

[65] J. D. McCurdy, F. T. Enders, A. Jones et al., "Detection of cytomegalovirus in patients with inflammatory bowel disease: where to biopsy and how many biopsies?," Inflammatory Bowel Diseases, vol. 21, no. 12, pp. 2833-2838, 2015.

[66] T. Iida, K. Ikeya, F. Watanabe et al., "Looking for endoscopic features of cytomegalovirus colitis," Inflammatory Bowel Diseases, vol. 19, no. 6, pp. 1156-1163, 2013.

[67] T. Yoshino, H. Nakase, S. Ueno et al., "Usefulness of quantitative real-time PCR assay for early detection of cytomegalovirus infection in patients with ulcerative colitis refractory to immunosuppressive therapies," Inflammatory Bowel Diseases, vol. 13, no. 12, pp. 1516-1521, 2007.

[68] K. Matsuoka, Y. Iwao, T. Mori et al., "Cytomegalovirus is frequently reactivated and disappears without antiviral agents in ulcerative colitis patients," The American Journal of Gastroenterology, vol. 102, no. 2, pp. 331-337, 2007.

[69] J. Chun, C. Lee, J. Kwon et al., "Usefulness of the cytomegalovirus antigenemia assay in patients with ulcerative colitis," Intestinal Research, vol. 13, no. 1, pp. 50-59, 2915.

[70] H. H. Herfarth, M. D. Long, T. C. Rubinas, M. Sandridge, and M. B. Miller, "Evaluation of a non-invasive method to detect cytomegalovirus (CMV)-DNA in stool samples of patients with inflammatory bowel disease (IBD): a pilot study," Digestive Diseases and Sciences, vol. 55, no. 4, pp. 1053-1058, 2010.

[71] T. Ganzenmueller, J. Kluba, J. U. Becker, O. Bachmann, and A. Heim, "Detection of cytomegalovirus (CMV) by real-time PCR in fecal samples for the non-invasive diagnosis of CMV intestinal disease," Journal of Clinical Virology, vol. 61, no. 4, pp. 517-522, 2014.

[72] E. J. Bini and E. H. Weinshel, "Endoscopic evaluation of chronic human immunodeficiency virus-related diarrhea: is colonoscopy superior to flexible sigmoidoscopy?," The
American Journal of Gastroenterology, vol. 93, no. 1, pp. 5660, 1998.

[73] K. A. Papadakis, J. K. Tung, S. W. Binder et al., "Outcome of cytomegalovirus infections in patients with inflammatory bowel disease," The American Journal of Gastroenterology, vol. 96, no. 7, pp. 2137-2142, 2001.

[74] Y. S. Kim, Y.-H. Kim, J. S. Kim et al., "Long-term outcomes of cytomegalovirus reactivation in patients with moderate to severe ulcerative colitis: a multicenter study," Gut Liver, vol. 8, no. 6, pp. 643-647, 2014.

[75] J. Kishore, U. Ghoshal, U. C. Ghoshal et al., "Infection with cytomegalovirus in patients with inflammatory bowel disease: prevalence, clinical significance and outcome," Journal of Medical Microbiology, vol. 53, no. 11, pp. 1155-1160, 2004.

[76] S. Matsumoto and Y. Yoshida, "What are the factors that affect hospitalization and surgery for aggravation of ulcerative colitis?" European Journal of Gastroenterology \& Hepatology, vol. 26, no. 3, pp. 282-287, 2014.

[77] A. Gauss, S. Rosenstiel, P. Schnitzler et al., "Intestinal cytomegalovirus infection in patients hospitalized for exacerbation of inflammatory bowel disease," European Journal of Gastroenterology \& Hepatology, vol. 27, no. 6, pp. 712-720, 2015.

[78] X. Liao, S. L. Reed, and G. Y. Lin, "Immunostaining detection of cytomegalovirus in gastrointestinal biopsies: clinicopathological correlation at a large academic health system," Gastroenterology Research, vol. 9, no. 6, pp. 92-98, 2016.

[79] A. Jones, J. D. McCurdy, E. V. Loftus et al., "Effects of antiviral therapy for patients with inflammatory bowel disease and a positive intestinal biopsy for cytomegalovirus," Clinical Gastroenterology and Hepatology, vol. 13, no. 5, pp. 949955, 2015.

[80] A. Kandiel and B. Lashner, "Cytomegalovirus colitis complicating inflammatory bowel disease," The American Journal of Gastroenterology, vol. 101, no. 12, pp. 2857-2865, 2006.

[81] L. Beswick, B. Ye, and D. R. Van Langenberg, "Toward an algorithm for the diagnosis and management of CMV in patients with colitis," Inflammatory Bowel Diseases, vol. 22, no. 12, pp. 2966-2976, 2016.

[82] T. Fukuchi, H. Nakase, M. Matsuura et al., "Effect of intensive granulocyte and monocyte adsorptive apheresis in patients with ulcerative colitis positive for cytomegalovirus," Journal of Crohn's and Colitis, vol. 7, no. 10, pp. 803-811, 2013.

[83] B. E. Sands, W. J. Sandborn, B. Feagan et al., "A randomized, double-blind, sham-controlled study of granulocyte/monocyte apheresis for active ulcerative colitis," Gastroenterology, vol. 135, no. 2, pp. 400-409, 2008.

[84] C. V. Paya, E. Marin, M. Keating, R. Dickson, M. Porayko, and R. Wiesner, "Solid organ transplantation: results and implications of acyclovir use in liver transplants," Journal of Medical Virology, vol. 41, no. S1, pp. 123-127, 1993.

[85] R. R. Razonable and A. Humar, "Cytomegalovirus in solid organ transplantation," American Journal of Transplantation, vol. 13, no. s4, pp. 93-106, 2013.

[86] I. Lautenschlager, L. Halme, K. Höckerstedt, L. Krogerus, and E. Taskinen, "Cytomegalovirus infection of the liver transplant: virological, histological, immunological, and clinical observations," Transplant Infectious Disease, vol. 8, no. 1, pp. 21-30, 2006. 
[87] R. R. Razonable and V. C. Emery, "Management of CMV infection and disease in transplant patients. 27-29 February 2004," Herpes, vol. 11, no. 3, pp. 77-86, 2004.

[88] A. Fica, C. Cervera, N. Pérez et al., "Immunohistochemically proven cytomegalovirus end-organ disease in solid organ transplant patients: clinical features and usefulness of conventional diagnostic tests," Transplant Infectious Disease, vol. 9, no. 3, pp. 203-210, 2007.

[89] V. Aguilera, T. Di Maira, I. Conde et al., "Cytomegalovirus reactivation in liver transplant recipients due to hepatitis $\mathrm{C}$ cirrhosis is associated with higher cardiovascular risk - an observational, retrospective study," Transplant International, vol. 31, no. 6, pp. 649-657, 2018.

[90] M. Hiyoshi, S. Tagawa, T. Takubo et al., "Evaluation of the AMPLICOR CMV test for direct detection of cytomegalovirus in plasma specimens," Journal of Clinical Microbiology, vol. 35, no. 10, pp. 2692-2694, 1997.

[91] I. G. Sia, J. A. Wilson, M. J. Espy, C. V. Paya, and T. F. Smith, "Evaluation of the COBAS AMPLICOR CMV MONITOR test for detection of viral DNA in specimens taken from patients after liver transplantation," Journal of Clinical Microbiology, vol. 38, no. 2, pp. 600-606, 2000.

[92] R. Patel, T. F. Smith, M. Espy et al., "A prospective comparison of molecular diagnostic techniques for the early detection of cytomegalovirus in liver transplant recipients," The Journal of Infectious Diseases, vol. 171, no. 4, pp. 1010-1014, 1995.

[93] M. P. Landini, T. Lazzarotto, G. T. Maine, A. Ripalti, and A. R. Flanders, "Recombinant mono- and polyantigens to detect cytomegalovirus-specific immunoglobulin $\mathrm{M}$ in human sera by enzyme immunoassay," Journal of Clinical Microbiology, vol. 33, no. 10, pp. 2535-2542, 1995.

[94] V. W. Halling, G. T. Maine, C. M. Groettum et al., "Clinical evaluation of a new recombinant antigen-based cytomegalovirus immunoglobulin $\mathrm{M}$ immunoassay in liver transplant recipients," Transplantation, vol. 71, no. 3, pp. 395-397, 2001.

[95] U. Navaneethan, P. G. K. Venkatesh, and J. Wang, "Cytomegalovirus ileitis in a patient after liver transplantationdifferentiating from de novo IBD," Journal of Crohn's and Colitis, vol. 5, no. 4, pp. 354-359, 2011.

[96] S. M. Lepinski and J. W. Hamilton, "Isolated cytomegalovirus ileitis detected by colonoscopy," Gastroenterology, vol. 98, no. 6, pp. 1704-1706, 1990.

[97] D. Lowance, H.-H. Neumayer, C. M. Legendre et al., "Valacyclovir for the prevention of cytomegalovirus disease after renal transplantation," The New England Journal of Medicine, vol. 340, no. 19, pp. 1462-1470, 1999.

[98] K. Mumtaz, N. Faisal, S. Husain, A. Morillo, E. L. Renner, and P. S. Shah, "Universal prophylaxis or preemptive strategy for cytomegalovirus disease after liver transplantation: a systematic review and meta-analysis," American Journal of Transplantation, vol. 15, no. 2, pp. 472-481, 2015.

[99] H. H. Hirsch, I. Lautenschlager, B. A. Pinsky et al., "An international multicenter performance analysis of cytomegalovirus load tests," Clinical Infectious Diseases, vol. 56, no. 3, pp. 367-373, 2013.

[100] I. G. Sia, J. A. Wilson, C. M. Groettum, M. J. Espy, T. F. Smith, and C. V. Paya, "Cytomegalovirus (CMV) DNA load predicts relapsing CMV infection after solid organ transplantation," The Journal of Infectious Diseases, vol. 181, no. 2, pp. 717720, 2000.
[101] A. J. Eid, S. K. Arthurs, P. J. Deziel, M. P. Wilhelm, and R. R. Razonable, "Clinical predictors of relapse after treatment of primary gastrointestinal cytomegalovirus disease in solid organ transplant recipients," American Journal of Transplantation, vol. 10, no. 1, pp. 157-161, 2010.

[102] B. J. Gardiner, J. K. Chow, L. L. Price, N. E. Nierenberg, D. M. Kent, and D. R. Snydman, "Role of secondary prophylaxis with valganciclovir in the prevention of recurrent cytomegalovirus disease in solid organ transplant recipients," Clinical Infectious Diseases, vol. 65, no. 12, pp. 2000-2007, 2017.

[103] D. C. Brennan, C. Legendre, D. Patel et al., "Cytomegalovirus incidence between everolimus versus mycophenolate in de novo renal transplants: pooled analysis of three clinical trials," American Journal of Transplantation, vol. 11, no. 11, pp. 2453-2462, 2011.

[104] H.-A. Myhre, D. Haug Dorenberg, K. I. Kristiansen et al., "Incidence and outcomes of ganciclovir-resistant cytomegalovirus infections in 1244 kidney transplant recipients," Transplantation, vol. 92, no. 2, pp. 217-223, 2011.

[105] A. P. Limaye, L. Corey, D. M. Koelle, C. L. Davis, and M. Boeckh, "Emergence of ganciclovir-resistant cytomegalovirus disease among recipients of solid-organ transplants," The Lancet, vol. 356, no. 9230, pp. 645-649, 2000.

[106] F. ChaerEl, D. P. Shah, and R. F. Chemaly, "How I treat resistant cytomegalovirus infection in hematopoietic cell transplantation recipients," Blood, vol. 128, no. 23, pp. 2624-2636, 2016.

[107] K. Ayre, B. F. Warren, K. Jeffery, and S. P. L. Travis, “The role of CMV in steroid-resistant ulcerative colitis: a systematic review," Journal of Crohn's and Colitis, vol. 3, no. 3, pp. 141-148, 2009.

[108] C. Lumbreras, O. Manuel, O. Len, I. J. M. ten Berge, D. Sgarabotto, and H. Hirsch, "Cytomegalovirus infection in solid organ transplant recipients," Clinical Microbiology and Infection, vol. 20, pp. 19-26, 2014. 


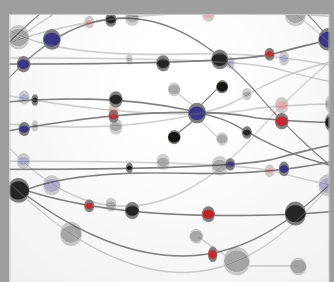

The Scientific World Journal
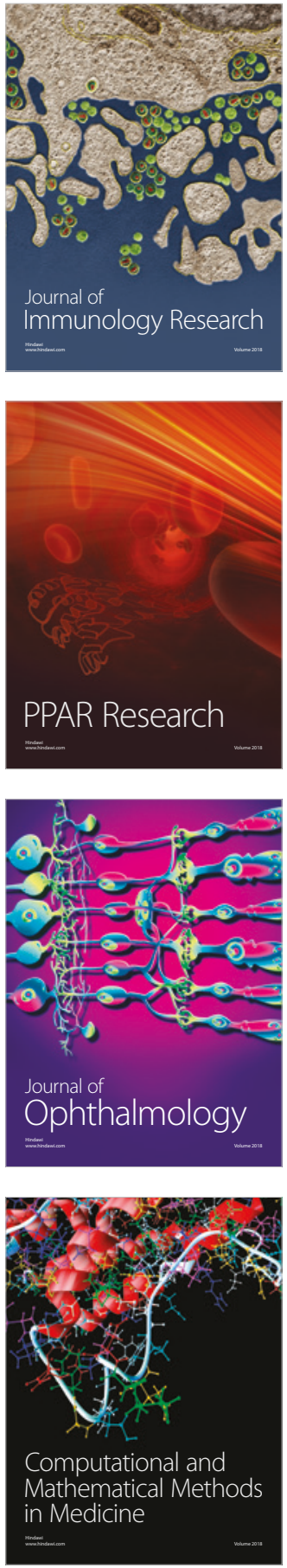

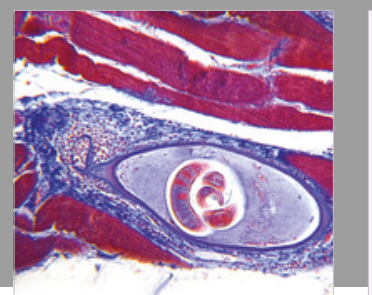

Gastroenterology Research and Practice

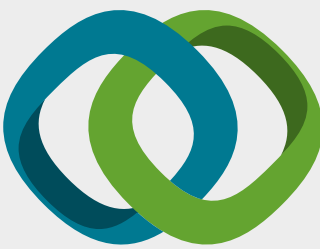

\section{Hindawi}

Submit your manuscripts at

www.hindawi.com
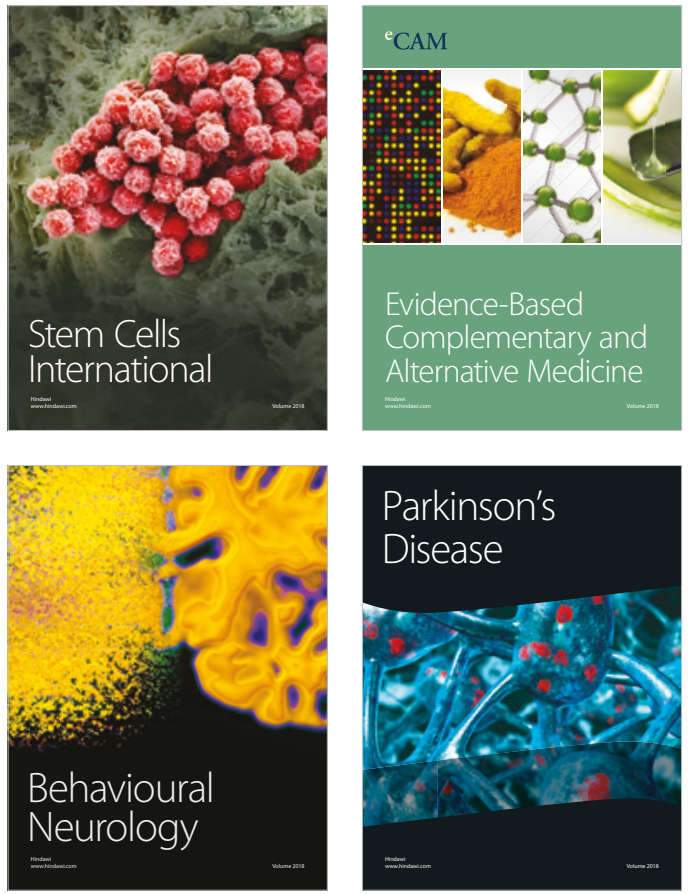

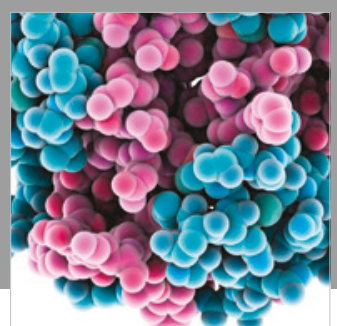

ournal of

Diabetes Research

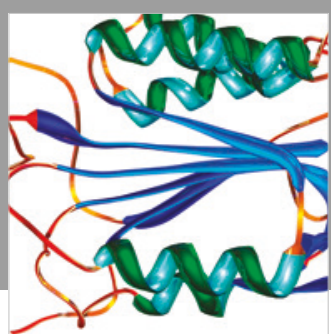

Disease Markers
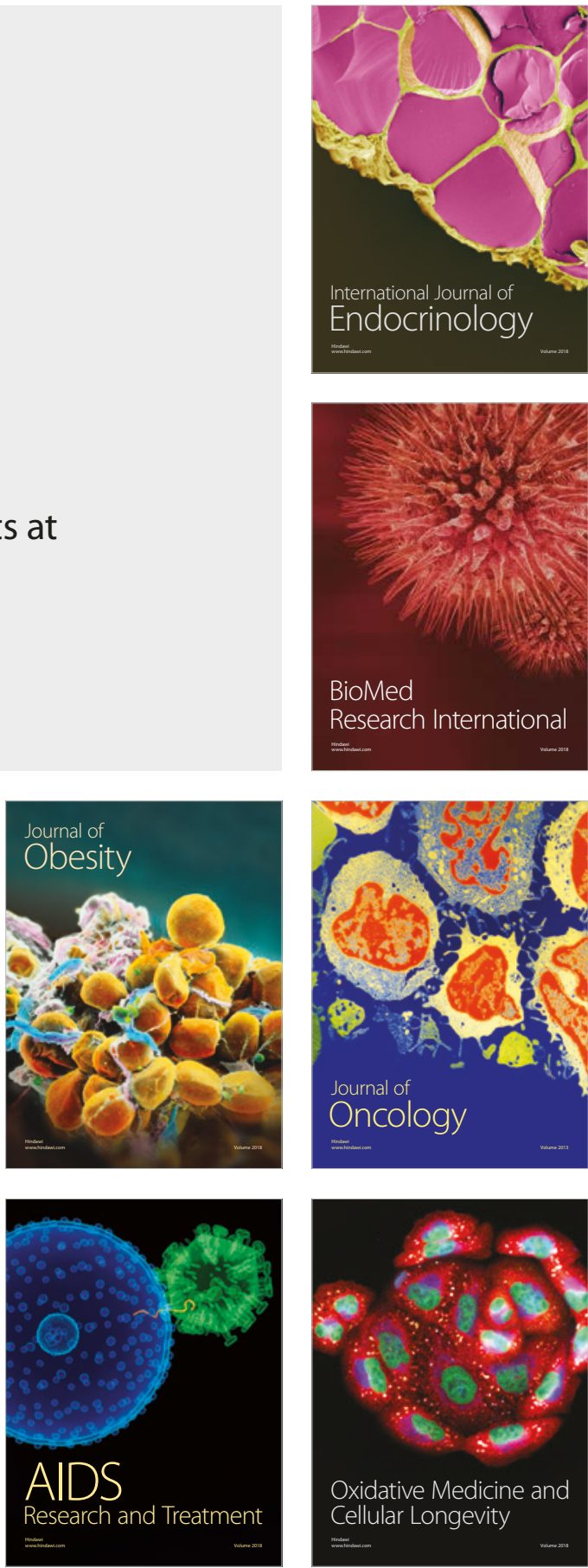